\title{
THE USE OF TEMPORARY MINI-IMPLANTS FOR FIXED TEMPORARY RESTORATION SUPPORT AT IMPLANT TREATMENT OF TOTALLY EDENTULOUS MAXILLA
}

\author{
Metodi Abadzhiev \\ Prosthodontic Department, Faculty of Dental Medicine, \\ Medical University - Varna
}

\section{SUMMARY:}

The matter of providing temporary restorations is of great importance at totally edentulous patients, wishful for fixed restorations over implants. Tempotary full denture, relined with soft resin, is the easiest solution, but there is a risk of failure of some of the implants. The possible solution in such cases is the use of temporary implants as a support for fixed structure.

Key words: temporary implants

\section{INTRODUCTION:}

At the implant treatment of totally edentulous patients is very important to provide an adequate temporary restoration that doesn't hinder the osteointegration process. The use of implants with smaller diameter (2.0$2.5 \mathrm{~mm}$ ) for fixed temporary restoration support allows the osteointegraton process to go freely. Besides, this ensures high esthetic and functional comfort for the patient from the moment of surgical intervention till the final completion of the treatment.

\section{METHODS AND MATERIALS:}

56 years old patient, male. (Fig. 1.) A smoker. The treatment plan for the maxilla includes extraction of all the remaining teeth (11 and 21), placement of 8 titanium implants Alpha Bio and 4 temporary implants with diameters 1.8 and $2.2 \mathrm{~mm}$. (Fig. 2.) The temporary fixed restoration is made chairside and is placed right after the operation (Fig. 3.); after 10 days is made long-term temporary structure of metal and resin (Fig. 4.). After the completion of the osteointegration period and the uncovering of the implants (Fig. 5.), the temporary implants are removed and the definitive metal-ceramic restoration is placed. (Fig. 6.)

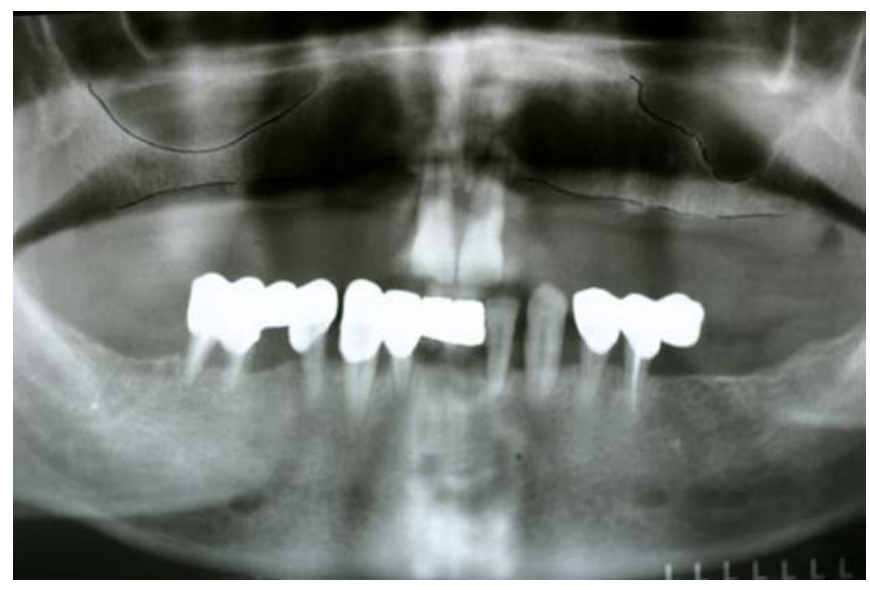

Fig. 1. OPG before treatment.

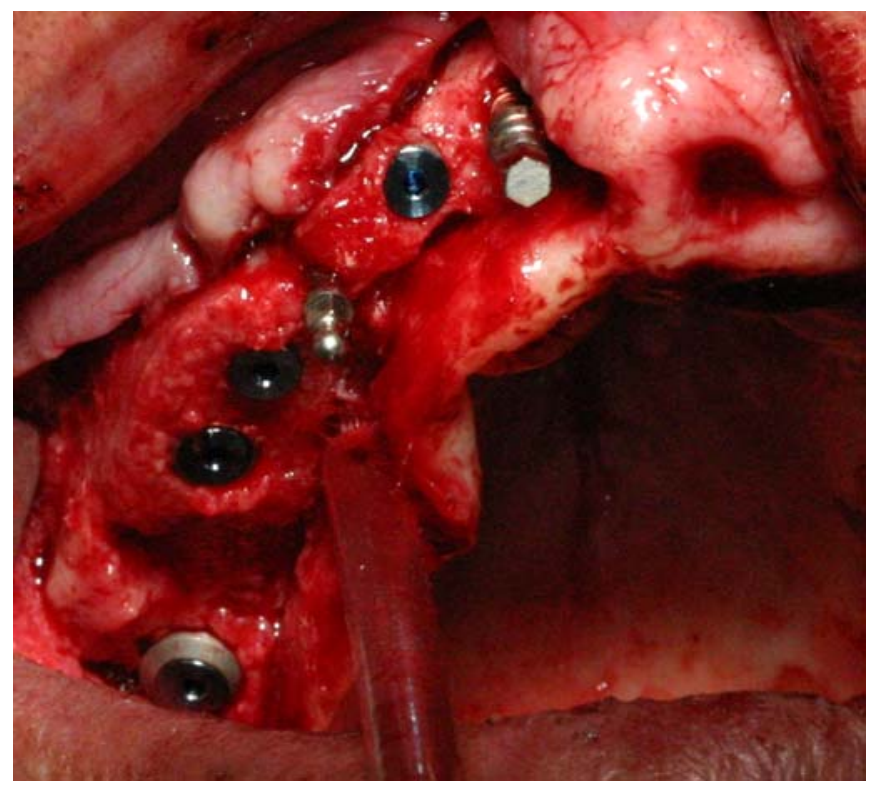

Fig. 2. The temporary and permanent implants, placed in first quadrant 


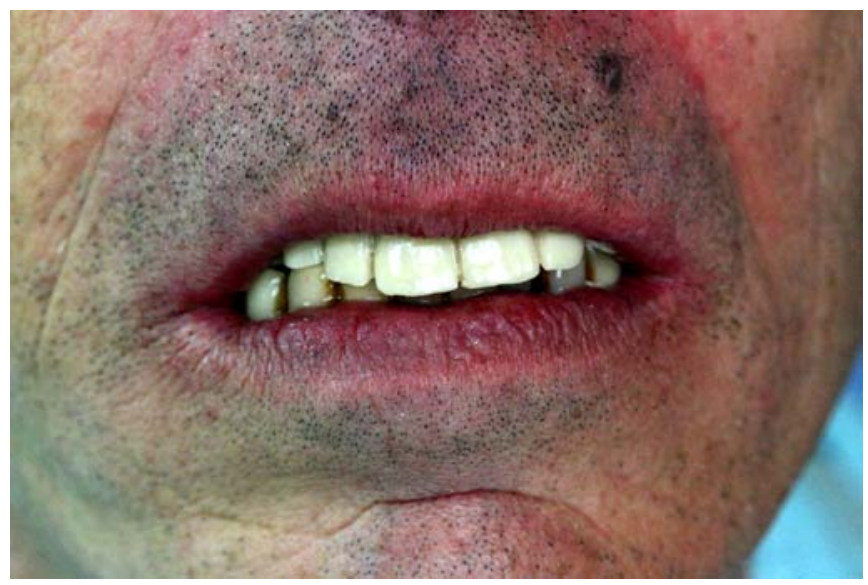

Fig. 3. Chairside made tempotary restoration, placed right after the operation.

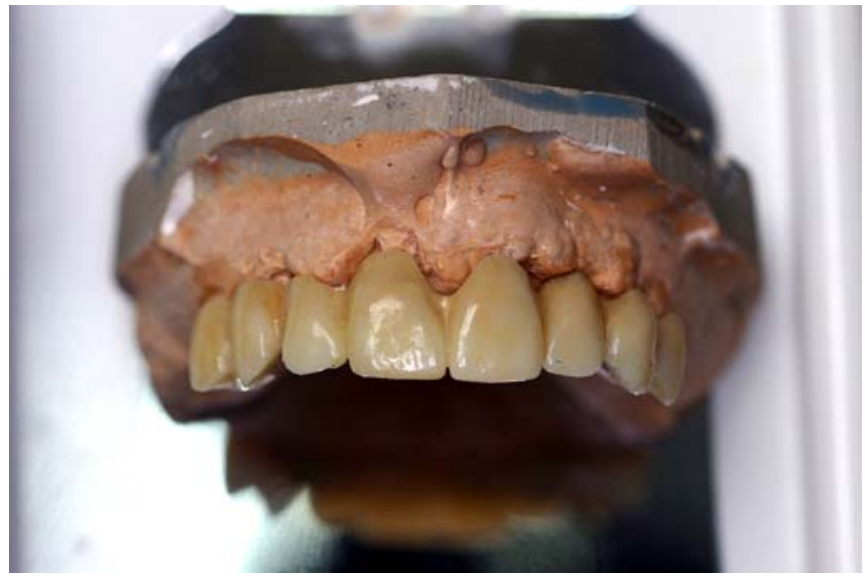

Fig. 4. Long-term temporary restoration.

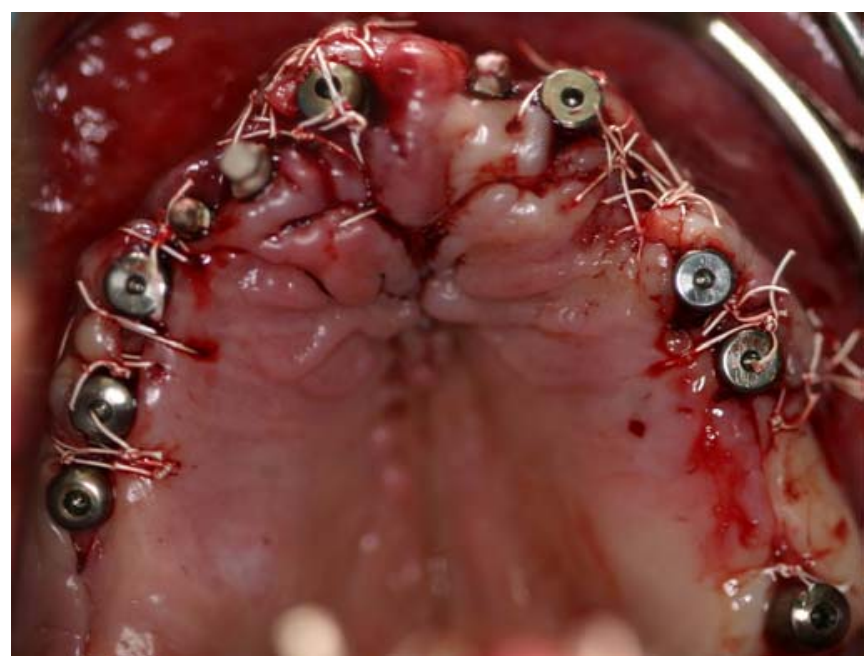

Fig. 5. Uncovering of the implants.

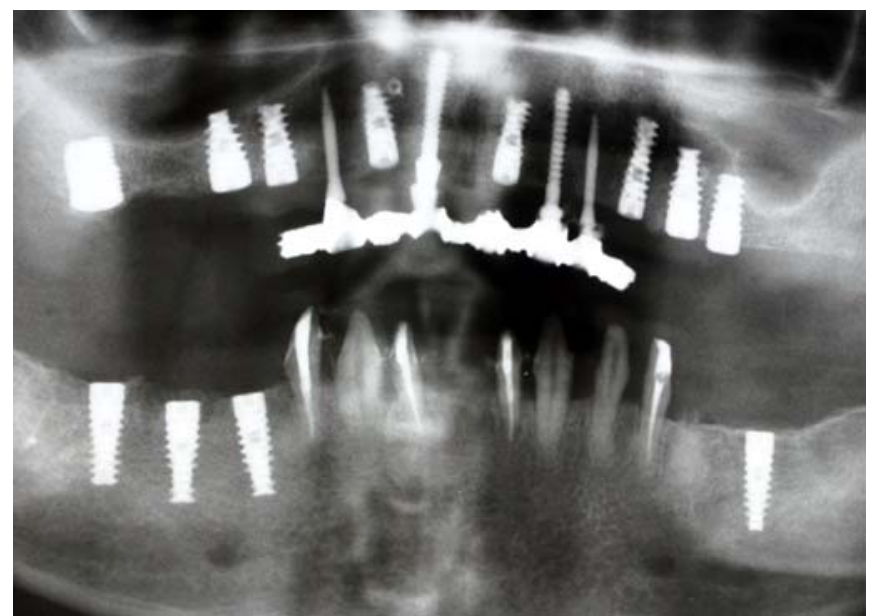

Fig. 6. OPG after the implants'placement .

\section{RESULTS:}

In the whole 4-months period the temporary implants created no problem of inflammatory or other character. They played their role as a support of the fixed temporary restoration that provided esthetic and functional comfort for the patient and safety for the osteointegration process.

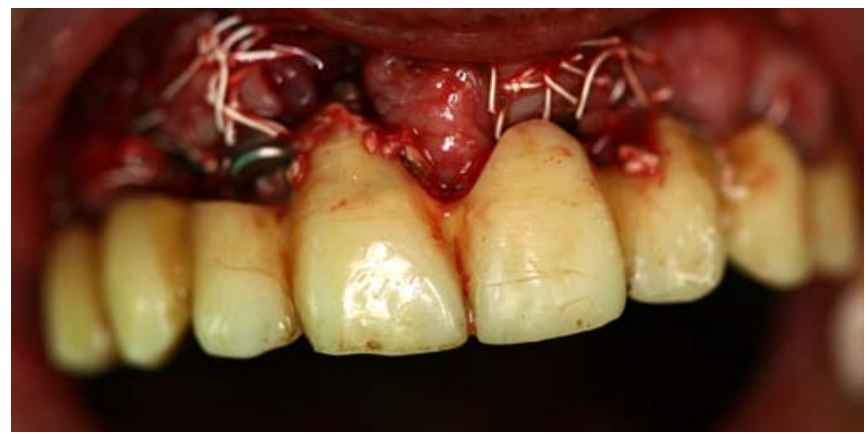

Fig. 7. The placed temporary restoration after the uncovering of the implants.

\section{DISCUSSION:}

Two of the temporary implants were removed easily $(13,23)-23$ still at the uncovering of the implants, since it was not stable. The implants with $2.2 \mathrm{~mm}$ diameter were osteointegrated. It was decided one of them to remain as an extra support for the final restoration. The removal of the other temporary implant was difficult, because of its osteointegration. All the 8 permanent implants were osteointegrated. After the additionalcreation of attached gingiva at the necessary places, the case was completed with the definitive prosthetic restoration. 


\section{CONCLUSION:}

It is recommended to use temporary implants to provide support for the fixed temporary restoration, whenever it's possible. This ensures the comfort for the patient and the safety for the implants in the osteointegration period.

\section{REFERENCES:}

1. Immediate restoration of smalldiameter implants in cases of partial posterior edentulism: a 4-year case series. Degidi M., Nardi D., Piattelli A. J. Periodontol. 2009 Jun; 80(6):1006-12.

2. Immediate functional loading of TiOblast dental implants in full-arch edentulous maxillae: a 3-year prospective study. Collaert B., De Bruyn H. Clin Oral Implants Res. 2008 Dec;19(12):1254-60.

3 . Immediate functional loading of implants placed with flapless surgery versus conventional implants in partially edentulous patients: a 3-year randomized controlled clinical trial.Cannizzaro G, Leone M., Consolo U., Ferri V., Esposito M. Int J Oral Maxillofac Implants. 2008 Sep-Oct; 23(5):867-75.

4. Optimization in multi-implant placement for immediate loading in edentulous arches using a modified surgical template and prototyping: a case report. Jayme S. J., Muglia V. A., de Oliveira R. R., Novaes A. B. Int J Oral Maxillofac Implants. 2008 Jul-Aug;23(4):759-62.
5. Provisional implants for immediate restoration of partially edentulous jaws: a clinical study. Krennmair G., Krainhцfner M., Weinlдnder M., Piehslinger E. Int J Oral Maxillofac Implants. 2008 Jul-Aug; 23(4): 717-25

6. Immediate loading using cross-arch fixed restorations in heavy smokers: nine consecutive case reports for edentulous arches. Romanos G. E., Nentwig G. H. Int J Oral Maxillofac Implants. 2008 May-Jun; 23(3):513-

Address for correspondence:

Metodi Abadzhiev

Prosthodontic Department, Faculty of Dental Medicine, Medical University - Varna

63, G. S. Rakovski Str., 9000 Varna, Bulgaria

E-mail: mabadjieff@yahoo.com 